Artigo recebido em

16/02/2015

Aprovado em

20/04/2015

Sean Hagen UFRGS -

hsean@uol.com.br

Professor de

Telejornalismo e Mídia Televi-

siva da Faculdade de

Biblioteconomia e

Comunicação. Mestre e doutor

Comunicação e

Informação pelo

PPGCOM \UFRGS
$O$ apagamento do

\section{correspondente estrangeiro}

no local do acontecimento

\section{telejornalístico: a passagem}

comensalista e a editorialização

da notícia narrada à distância

Sean Hagen

\section{Resumo}

A co-presença no acontecimento confere credibilidade ao jornalismo e ao jornalista frente às informações que publicizam. Essa ação é intensificada na passagem do repórter, espaço de afirmação e confirmação do fato narrado no telejornal. É no sentido de "construção de presença" - tipologia da reportagem definida por Fechine e Lima (2008) - que isso mais bem se percebe. Os telejornais da Rede Globo, no entanto, criaram uma nova função para a passagem do correspondente estrangeiro: em vez da ação de presenciar o acontecimento e narrar in loco, empregam uma abordagem editorializada e reforçam o viés político/econômico/cultural que a Rede Globo tem sobre determinados fatos estrangeiros. Essa prática constitutiva da reportagem é definida como passagem comensalista.

\section{Palavras-chave}

Telejornalismo, Correspondente Estrangeiro, Passagem, Editorialização da Notícia, Rede Globo.

\begin{abstract}
The co-presence at the event provides credibility to the journalism and to the journalist in the face of information that is been publicized. This action is increased in the reporter's stand up, which can be considered a space to affirm the narrative of facts in television newscast. It can be perceived more clearly in the sense of "building of presence" - typology of report defined by Fechine and Lima (2008). The Brazilian Rede Globo's newscasts, however, created a new role for the stand up of foreign correspondent: instead of being a witness of the events and tell the stories at where they occur, the correspondent applies an editorialized approach and strengths the political/economical/cultural bias that Rede Globo has about certain foreign facts. This constitutive practice of reporting is defined here as comensalistic stand up.
\end{abstract}

\section{Keywords}

TV Newscast, Foreign Correspondent, Stand Up, News Editorialization, Rede Globo. 


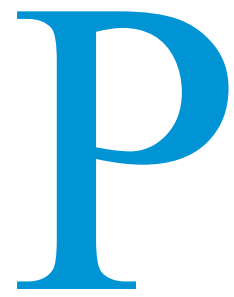

resenciar acontecimentos aos quais o público não tem acesso é um dos dispositivos de construção da credibilidade jornalística: espera-se encontrar o jornalista onde os fatos acontecem, observando, indagando, coletando informações para construir a notícia. E através da dialética acontecimento/presença a imagem do repórter se constrói acima do próprio jornalismo, alimentada, principalmente, pelo cinema estadunidense do século XX. A cultura contemporânea ainda trabalha com a imagem romântica do repórter como "testemunha ocular" que enfrenta perigos e adversidades para levar os fatos ao público. Essa imagem abrange desde o investigador durão e destemido que usa a força física para chegar aos fatos, até o cínico estrategista que se vale apenas da sagacidade para desvendar os intrincados processos em que os acontecimentos foram gerados.

Grande parte do que é produzido pelos jornais, no entanto, não prescinde da co-presença com o acontecimento para ser processado em notícia e ser credível para o público. É através do campo que essa qualificação se instaura, com os acontecimentos sendo processados em outro lugar, por outros repórteres, em muitas mediações, longe do veículo em que a notícia será publicada. Esse reprocessar de fatos, no entanto, apaga o sentido de co-presença para trabalhar com a proposição de que o campo jornalístico tem poder para abalizar tudo o que medeia, possibilitando que o jornalista que processa e assina a reportagem não seja o autor primeiro. Notícias de agência, notas apuradas por telefone, por e-mail, informações colhidas de outros veículos são espaços em que essa prática aparece cotidianamente, e é nessa inte- ração e apropriação de vozes, códigos e signos que o jornalismo se instaura. Não é um discurso de "primeira mão" justamente por tocar em diversas áreas ao mesmo tempo e incorporar, na própria metodologia de trabalho, essa prática (HAGEN, 2008, p.35). O conceito de "mapas culturais do mundo social" reforça a proposição da forte mediação presente na pragmática. "Este trazer de acontecimentos ao campo dos significados quer dizer, na essência, reportar acontecimentos invulgares e inesperados para os 'mapas de significado' que já constituem a base do nosso conhecimento cultural, no qual o mundo social já está 'traçado"” (HALL et al., 1993, p. 226).

Mas há um apagamento dessa prática quando se constroem as múltiplas imagens dos jornalistas dentro e fora da realidade. No Brasil, grande parte dessa imagem é engendrada pela Rede Globo, maior produtora de informação jornalística do país, além de líder na produção de entretenimento, com programas exportados para todo o mundo. Na ficção, o telejornal e os repórteres, por serem a ponta do campo jornalístico mais fácil de ser identificada e copiada - através da câmera, do microfone, dos blocos de anotação e dos indefectíveis paletó/gravata e tailleurs - aparecem sempre que um acontecimento na trama irrompe, reforçando o imaginário de que é pelo jornalismo que a verdade chega à sociedade.

Se a ficção trabalha apenas com a aparência mais externa do jornalismo para chegar a uma verossimilhança possível com o real, o campo jornalístico não deixa de aproveitar essa imagem ficcional, quando convém, para reforçar a premissa de que está presente em todo lugar a todo momento. Essas "pinceladas" de 
onipresença se sobressaem acima de outras características apagando peculiaridades do jornalismo pouco glamourosas e escondendo o que é intrínseco ao campo:

\section{Espera-se ver o jornalista onde os fatos acontecem, observando, construindo a notícia}

o jornalismo é uma estratégia discursiva amparada no rigor com que apura os fatos gerados pelo acontecimento através da objetividade, da especialização de quem fala e do cruzamento de fatos e fontes.

Decifrar a realidade fragmentada e reconstruí-la sob a ordem da narração exige do jornalista o domínio de técnicas de estratégias discursivas particulares, inscritas nos elementos do contrato de comunicação de um gênero discursivo totalmente singular distinto de qualquer outro gênero do discurso e mediado, desde sempre, por sua missão pública (BENETTI, 2008, p. 25).

\section{Distanciamentos e aproximações}

Entre presenciar o acontecimento, e narrá-lo através do relato de outra fonte, o jornalismo se constrói e instaura, ora ressaltando que esteve presente no espaço e no tempo da ação - através da matéria assinada e da presença do repórter na passagem $^{1}-$, ora fazendo o apagamento de que constrói um discurso "sobre" - amparado no relato de outros jornalistas ou nas informações captadas à distância. Mas por que se dá tanta importância à ação de presenciar o acontecimento?

O acontecimento jornalístico é o "ponto zero" da significação, como define Rodrigues $^{2}$ (1997a, p. 98), o momento primordial da criação. Sem ele, não há jornalismo, não há fazeres e práticas, não há profissão. É dessa “matéria-prima” que o jornalismo se alimenta, mediando os "mapas culturais" presentes na sociedade. "É acontecimento tudo aquilo que irrompe na superfície lisa da história de entre uma diversidade aleatória de fatos virtuais. Pela sua natureza, o acontecimento situa-se, portanto, algures na escala das probabilidades de ocorrência, sendo tanto mais imprevisível quanto menos provável for a sua realização" (RODRIGUES, 1997a, p. 98).

Ao mesmo tempo, é preciso entender como se estabelece a relação entre o jornalismo e o acontecimento. As nuances presentes na identificação, mediação e publicização dos fatos delimitam o campo e formatam os jornalistas, alimentando a imagem que têm de si e com a qual se relacionam com o público. Há três distinções que precisam ser feitas na relação que se estabelece com o acontecimento (RODRIGUES, 1997b, p.1): o testemunho da experiência, a transmissão da experiência e a relação simbólica da comunicação com a experiência. A relação simbólica se aproxima dos "mapas culturais" de Hall e, por isso, o interesse recai sobre as duas primeiras.

No "testemunho", o acontecimento é narrado para alguém que não o presenciou; o destinador busca controlar a veracidade da narrativa e cabe ao destinatá-
${ }^{1}$ A passagem é o momento em que o repórter faz a entrada ao vivo na reportagem. Há muitas funções e definições para a passagem, não havendo um consenso teórico sobre seu estatuto. Serve desde uma simples "assinatura" do repórter até como forma de contextualizar informações difíceis para a qual não há imagens, passando pela função de dar credibilidade à informação ao fazer contato "olho no olho" com o público. No item Presença Periférica o assunto será mais bem abordado.

${ }^{2}$ As peculiaridades presentes na definição de acontecimento jornalístico impossibilitam o consenso sobre seu estatuto e abrangência no campo. Aqui, filio-me à visão de Rodrigues pela especificidade que apresenta frente à pragmática da profissão e a possibilidade de ser operacionalizada pelo analista, abrangendo duas importantes áreas para a pesquisa. Outras perspectivas podem ser encontradas em Katz (1993), Molotch e Lester (1993), Mouillaud (1997) e Charaudeau (2006). 
rio imputar credibilidade ao fato narrado amparado no que conhece do narrador.

${ }^{3}$ As duas terminologias são usadas por Thompson na abordagem da mídia com o público. Mas é preciso lembrar que, antes de ser um profissional, o jornalista já foi público e continuará sendo concomitantemente com outras posições que ocupe na sociedade, alimentando cada uma delas nessa reversibilidade e trazendo uma multiplicidade de olhares - subjetivos - para o jornalismo.

${ }^{4}$ Segundo Thompson (2002, pp. 183-184), “[...] self é um projeto simbólico que o indivíduo constrói ativamente [...] com os materiais simbólicos que lhe são disponiveis, materiais com que ele vai tecendo uma narrativa coerente da própria identidade. Esta é uma narrativa que vai se modificando com o tempo, à medida que novos materiais, novas experiências vão entrando em cena e gradualmente redefinindo a sua identidade no curso da trajetória de sua vida. Dizer a nós mesmos e aos outros o que somos é recontar as narrativas - que são continuamente modificadas neste processo - de como chegamos até onde estamos e para onde estamos indo daqui para frente".

${ }^{5} A$ "experiência mediada" se ampara na "quase-interação mediada"

(Thompson, 2008). Ela possibilita que os indivíduos alarguem seus horizontes e estabeleçam novos parâmetros no processo de auto-formação. Os materiais simbólicos que ajudam na formação do self, agora, não dependem mais das relações locais de poder para se espelhar. $O$ conhecimento é adquirido de forma múltipla em múltiplos veículos da mídia. As formas mediadas de comunicação enriquecem a organização reflexiva do self, propiciando uma variada gama de materiais simbólicos para essa construção. Agindo como ideais simbólicos, propiciam que o indivíduo organize a vida no seu entorno, tirando sentido disso.
Existe, muitas vezes e em especial no meio jornalístico, a pretensão de valorizar esta modalidade de comunicação da experiência, em nome da autenticidade da comunicação e da vontade de eliminação das eventuais distorções que os dispositivos de mediação podem provocar. É o caso da valorização do "direto" [ao vivo] tão em voga atualmente. Trata-se de uma visão ingênua tanto da experiência como da comunicação, na medida em que consiste no apagamento da intervenção inevitável e incontornável da linguagem, não só para a comunicação mas também para a constituição da própria experiência (RODRIGUES, 1997b, p.1).

$\mathrm{Na}$ "transmissão", o acontecimento narrado é de "segunda mão", ou seja, não teve co-presença do narrador, vem de outra fonte. Neste caso, a credibilidade tem de ir além do destinador, deve abarcar a fonte primeira, que viveu a experiência in loco. Mas é preciso fazer uma distinção entre o "testemunho" e a "transmissão".

No testemunho, o destinador funda uma partilha originária de experiência, ao passo que na cadeia de transmissão, os destinadores sucessivos constituem a modalidade tradicional da experiência, no sentido mais genuíno do termo. Neste segundo caso, cada um dos destinatários da mensagem assume- -se também como destinador. É esta duplicidade de estatutos de cada um dos elos da transmissão que forma a cadeia ininterrupta que caracteriza a tradição (RODRIGUES, 1997b, p.3).

O campo jornalístico abaliza esse tipo de "transmissão" quando publica o acontecimento na forma em que chega a notícia ou a reprocessando com novos fatos e mediações, dando o crédito à fonte - quando vinda de agências noticiosas, não só pela credibilidade que possuem, mas em respeito legal aos direitos autorais - ou simplesmente retransmitindo o fato sem imputar autoria, amparando a notícia na credibilidade do jornal, da empresa e do próprio campo.

A diferença entre presenciar ou estabelecer uma relação "virtual" com o fato através da narração transforma a maneira como compreendemos as coisas e o valor imputado a elas. Por isso é importante para o jornalismo fazer crer que está onde o fato emerge. Thompson (2008), amparado em autores da hermenêutica e fenomenologia, aponta duas formas de experiência ${ }^{3}$ pelas quais o homem se relaciona. A "experiência vivida" é formada no curso diário da vida de maneira imediata e contínua, e propicia um conhecimento inquestionável

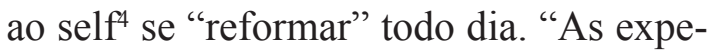
riências vividas formam um ambiente para o self; é a experiência de eventos que ocorrem (ou de outros que estão situados) imediatamente no mesmo local espaço-temporal, e que o self pode potencialmente influenciar através de suas ações (ou com quem ela pode potencialmente interagir)" (THOMPSON, 2008, p. 199). A “experiência mediada" ${ }^{5}$ trabalha com acontecimentos distantes no espaço e, possivelmente, 
no tempo, que não recebem a interferência do indivíduo. "Por isso a experiência mediada afeta o self de um modo tênue, intermitente e seletivo. A experiência mediada não é um fluxo contínuo, mas uma sequência descontínua de experiência que têm vários graus de relevância para o self" (THOMPSON, 2008, p. 199).

A co-presença junto ao acontecimento é um bem maior buscado no jornalismo, mas não uma regra. Para além de sua função de asseverar ${ }^{6}$ o que foi vivenciado, subjetivamente cria um ambiente de credibilidade para as informações em que os jornalistas não puderam desfrutar da experiência direta, no local e no tempo dos fatos. O acontecimento é um processo complexo capaz de gerar organização e desorganização social, em variada intensidade: "a intervenção do relato jornalístico em acontecimentos complexos ou com elevado potencial de complexidade, pode ampliar, em novos sucessos, a rota do processo e, até, desencadear processos derivados nas tramas sociais" (CHAPARRO, 1994, p. 114, grifos do autor).

\section{Presença periférica}

No telejornalismo, o espaço reservado à passagem do repórter é, ao mesmo tempo, um processamento do acontecimento em reportagem e a afirmação da presença física onde o fato se desdobra. Cabe ao repórter asseverar o que viu fazendo as devidas mediações para transformar os fatos em notícia. Está enquadrado na definição de "testemunho": não tem a credibilidade do saber narrativo contestada porque pode afirmar com propriedade o que presenciou. É na crença desse relato veraz e ocular que a credibilidade com o público se instaura na reportagem do telejornal: só deve haver passagem quando se pode afirmar o que se viu e mediou.

Em um esforço teórico para sistematizar a função de passagem, Fechine e Lima (2008, p. 10) encontraram sete funções desempenhadas dentro da reportagem, lugar onde essa unidade se instaura: 1) contextualização ou recuperação de informações; 2) desdobramento do fato/fenômeno; 3 ) indicação ou realce de percurso; 4) hierarquização de informações; 5) gerenciamento de atenção; 6) proposição de juízos interpretativos; 7) construção de presença.

Mais do que uma tipologia estanque, em que as classificações não são intercambiáveis, o dia a dia da redação de um telejornal mostra que todas essas funções constituem tanto a reportagem quanto o repórter, criando uma circularidade em que a notícia é o bem maior na ponta final. As partes definem o todo ancorado no "ponto zero da comunicação": o acontecimento. Assim, a "construção de presença" perpassa todas as outras seis funções reafirmando a credibilidade de quem presenciou, questionou e mediou o acontecimento onde quer que ele irrompa.

Os telejornais da Rede Globo, e mais especificamente o Jornal Nacio$\mathrm{nal}^{7}$, no entanto, quebram esse "contrato" ao criar uma nova função para a presença do repórter: a passagem comensalista. O "comensalismo" é um termo usado na biologia para definir [...] uma relação interespecífica, pela qual todos os integrantes vivem regularmente associados e pela qual um procura alimento no outro, sem contudo causar-lhe dano [...]. Relação que envolve tanto a competição quanto a cooperação entre aqueles que participam de uma divisão integrada
${ }^{6}$ Para Van Dijk (1990), esse é o verbo que define o ato de fala próprio do campo jornalístico.

${ }^{7}$ É preciso ressaltar que o JN explora com maestria a co-presença no lugar de desenvolvimento do fato na busca por maior credibilidade. "O JN também enaltece sua condição de chegar aos locais onde os fatos acontecem. A passagem do repórter no local do acontecimento é uma das marcas mais fortes do JN e um dos indícios, aliados a entradas ao vivo e a seus correspondentes internacionais, de sua retórica de jornalismo de informação" (GOMES e GOMES, 2007, p. 87). No entanto, ressalto que todos os telejornais da Globo usam da mesma estratégia de comunicação em reportagens internacionais. $O J N$, por ser o mais paradigmático e copiado, tanto dentro quanto fora da emissora, propicia uma análise de referência para os outros jornais. 
de trabalho. Processo simbiótico quando os conviventes utilizam as mesmas condições de vida sem entretanto se afetarem mutuamente (FORNARI, 2001, p.62).

De forma mais abrangente e genérica, também pode ser definido como "justaposição não competitiva de indivíduos ou grupos, os quais, habitando a mesma área, têm necessidades e interesses diferentes, de maneira que entre eles não se observa nem conflito nem cooperação" (MICHAELIS, 2009).

A função da passagem comensalista é justamente isso: buscar a associação com um acontecimento ocorrido em outro lugar para "se alimentar" da informação gerada; não divide o mesmo espaço/tempo com os fatos ocorridos e apaga a função primeira de "construção de presença". Ao retirar a importância da informação construída in

\section{A passagem comensalista busca associação com fato ocorrido em outro lugar}

\begin{abstract}
${ }^{8}$ Texto de abertura lido ao vivo para chamar o vídeo tape da nota coberta ou reportagem (matéria). É um lead geralmente mais sucinto. Responde, essencialmente, a pergunta "o quê".
\end{abstract}

${ }^{9}$ http://jornalnacional. globo.com/Telejornais/JN/O, MUL1214073-10406,O0-PRESIDENTE+ AFASTADO+ QUER+RETR+O+

$P O D E R+E M+$ HONDURAS.html que justificasse a presença de um repórter. O mesmo aconteceu com a África do Sul, que teve um escritório funcionando até o final da Copa de 2010. Abrangendo América, Europa, Ásia e Oriente Médio menos Oceania -, a ideia de que faz uma "cobertura mundial" dos fatos é o sentido mais evidente pelo telejornalismo da Globo. Ao reafirmar nas cabeças ${ }^{8}$ de matéria a presença dos correspondentes na região em que os fatos acontecem, há uma associação com o sentido de presença que apaga a distância entre o lugar em que o acontecimento se desenrola e o lugar onde o repórter constrói a passagem para narrar o fato.

Na edição de 30 de junho de 2009 do Jornal Nacional, William Bonner leu a seguinte cabeça: "O presidente de Honduras, afastado por um golpe militar, anunciou hoje que pretende voltar ao país e retomar o poder com apoio das Nações Unidas. Quem informa é o correspondente na América Latina, Carlos de Lannoy"9. Pela chamada da matéria, depreende-se aquilo que se espera do jornalismo: o correspondente foi enviado para onde o acontecimento eclode para narrar os fatos após averiguar, em primeira mão, o que está acontecendo. Mas não é isso que ocorre. Depois de explicar a situação no país e como se deu o golpe, o repórter faz a passagem encaminhando o assunto para o encerramento: "Há uma grande expectativa sobre a volta de Zelaya, já que o novo governo prometeu que ele será preso e julgado quando desembarcar no país. Zelaya disse que viajará acompanhado de representantes das Nações Unidas, da Organização dos Estados Americanos e dos presidentes do Equador, Rafael Correa, e da Argentina, Cristina Kirchner, que aceitaram o convite". É surpreendente que, 
após ser anunciado como "correspondente da Rede Globo na América Latina" e narrar todo o acontecimento pós-golpe, Dellanoy apareça em Buenos Aires, a 6.215 quilômetros de Tegucigalpa, cidade onde se desenrola o acontecimento. Como o repórter pode asseverar o que viu e fazer a mediação estando a uma distância tão grande? Se o critério de noticiabilidade ${ }^{10}$ usado aqui, supostamente, for a proximidade, a capital do Brasil é mais próxima da hondurenha: 5.454 quilômetros, ou seja, 761 quilômetros a menos do que a capital argentina. Nenhum valor notícia explica a lógica dessa passagem comensalista. A alusão extremamente tênue de que a presidenta argentina poderia participar de uma comitiva com o presidente deposto não tem força como acontecimento para explicar a escolha do local da passagem. Todo o interesse está focado no golpe e na reação do presidente deposto, nunca na possível participação auxiliar de Cristina Kirchner.

A reiteração de que há um correspondente na América Latina para cobrir os fatos da região, mas na verdade faz a mediação jornalística a milhares de quilômetros do acontecimento, nada mais é do que imputar credibilidade ao poder econômico de ter um correspondente, e não à função que ele realmente deveria exercer. Não passa de uma estratégia de marketing, já que não há diferença em fechar a matéria em Brasília ou Buenos Aires quando se usam imagens de agências internacionais e os fatos vem apurados, em grande parte, por essas fontes. Ou será que a latinidade portenha é "melhor" do que a brasileira para contextualizar à distância os fatos e justificar a passagem do repórter longe do acontecimento?

A passagem comensalista pode ir além e apagar completamente o sentido de co-presença com o acontecimento para criar um sentido de indistinção, como se a espacialidade não fosse relevante na construção da notícia. Em 24 de abril de 2009, o Jornal Nacional mostrou uma matéria ${ }^{11}$ sobre o desemprego na Europa, enfocando especificamente três países: Alemanha, Inglaterra e Espanha. O peso maior da informação recaiu sobre os espanhóis, com quatro milhões de desempregados. O repórter entra com a passagem, então, para fazer uma análise mais aprofundada da questão e encerrar a matéria. "Os números de hoje são alarmantes e as previsões na Espanha são ainda piores. O país de 46 milhões de habitantes deve chegar ao início de 2011 com quase 5 milhões de pessoas procurando trabalho". Se por si só o texto já tinha um tom de catástrofe, o sentido de acontecimento deplorável fica ainda maior quando vemos o repórter Pedro Bassan falar direto de Portugal, com uma típica casa lisboeta ao fundo. Os espanhóis poderiam classificar de legítimo esse acontecimento ao verem sua realidade retratada a 503 quilômetros de Madri? Os dois países dividirem similaridades na língua e nos costumes latinos não os torna o mesmo, com realidades equivalentes. Nem mesmo dividirem espaço na Península Ibérica ou serem europeus. Nenhum acontecimento pode ter a pretensão de ser retratado à distância acreditando que partilhará do mesmo estatuto da co-presença. Aqui se instala o comensalismo, a busca por dividir algo que não é legitimamente seu, mesmo que isso não cause aparente problema.

O comensalismo que se faz co-presente, até quando essa presença não existe, tem a capacidade de atravessar continentes para alimentar o sentido asseverador. No JN de
${ }^{10}$ Pela sistematização feita por Moreira (2006) sobre os valores notícia de diversos autores, destacam-se: atualidade e ineditismo; importância (conseqüencia; amplitude e impacto; intensidade e gravidade; utilidade e serviço; notoriedade dos agentes); emoção e dramaticidade; entretenimento; suspense; excepcionalidade (extraordinário ou sensacional; incomum, insólito ou singular; mudança; imprevisível, inesperado ou surpreendente); conflito ou controvérsia; negatividade (infração ou ilegalidade; falha ou anormalidade; violência); proximidade.

${ }^{11} \mathrm{http}: / / j o r n a l n a-$ cional.globo.com/ Telejornais/JN/0,,MUL1097933-10406,00-ESPANHA+AGONIZA+$C O M+D E S E M P R E-$ GO+RECORDE.html

${ }^{12} \mathrm{http}: / / j o r n a l n a-$ cional.globo.com/ Telejornais/JN/0,,MUL1224926-10406,00-EUA+E+CO$\mathrm{REIA}+\mathrm{DO}+\mathrm{SUL}+\mathrm{SO}-$ FREM+ATAQUES $+C I-$ BERNETICOS.html 
9 de julho de 2009, a cabeça da matéria ${ }^{12}$ sobre ataques de hackers a sites estratégicos da Coreia do Sul e dos Estados Unidos frisa que a matéria foi mediada pelo correspondente da Globo na Ásia, alertando para a importância do repórter e da função que exerce. "Estados Unidos e Coreia do Sul voltaram a sofrer ataques de piratas de computadores através da internet. $\mathrm{O}$ correspondente na Ásia, Roberto Kovalick, informa que um dos alvos da ação de hoje foi o serviço secreto sul-coreano". Apesar de citar constantemente os Estados Unidos, o acontecimento genuíno está na Coréia do Sul, que conseguiu apreender computadores dos piratas que estavam tirando páginas do ar. Mas a ação não foi definitiva, conforme mostra a passagem: “Apesar das medidas, os piratas voltaram a atacar esta noite. Na mesma hora, várias páginas saíram do ar. Entre os alvos, bancos e a unidade das Forças Armadas americanas na Coreia do Sul. Foi o terceiro ataque seguido aos computadores do país". A temporalidade da narrativa, que fala do ataque "esta noite" na "Coreia do Sul" aos "computadores do país", leva a crer que o repórter está no local dos fatos, presenciou os acontecimentos que há pouco aconteceram - reforçado pela proximidade da expressão "esta noite" - e os processou em informação jornalística o mais rápido que pôde para entrar no telejornal do dia. A reportagem seria correta se Kovalick não estivesse em Tóquio, a 1.158 quilômetros de distância de Seul, separado pelo Mar do

${ }^{13} \mathrm{http}: / / j o r n a l n a c i o-$ nal.globo.com/Telejornais/JN/0,,MUL1228668-10406,O0-SOLDA$D O+N A Z I S T A+-$ $V A I+A O+B A N-$ CO+DOS+REUS+NA+ALEMANHA. html
Ásia é um continente indistinto - como se não fosse o maior do mundo -, onde todos os países e culturas são "similares", o que desobriga o repórter a fazer a passagem no lugar dos fatos. É a sofisticada construção do texto que cria o sentido de co-presença ao acontecimento. Se o público não tem como acessar pessoalmente as informações e, de forma geral, não "presencia" a distância que separa os dois países, fica mais fácil falsear o sentido de proximidade, um forte abalizador da credibilidade. A intenção da passagem comensalista fica ainda mais forte quando uma notícia com dois pólos definidos de acontecimento, um na América e outra na Europa, é processada em um terceiro continente, no Oriente Médio. Em 13 de julho de 2009, o Jornal Nacional apresentou a seguinte cabeça ${ }^{13}$ : "Promotores da Alemanha formalizaram hoje o indiciamento de um ucraniano acusado de ter trabalhado para os nazistas durante a Segunda Guerra Mundial. Ele responderá por quase 28 mil mortes, como conta, de Jerusalém, o correspondente Ari Peixoto". Diferentemente de outras nominações, o repórter não foi apresentado como "correspondente no Oriente Médio", a forma usual que o JN usa quando o jornalista não está no centro do acontecimento. Ao ressaltar que está baseando em Jerusalém, a "co-presença" com o fato ganha uma dimensão político-histórica. $\mathrm{O}$ ucraniano foi preso nos Estados Unidos, primeira instância do acontecimento; e foram os promotores da Alemanha quem formalizaram o pedido de indiciamento, segunda instância. Para justificar a escolha de Israel como lugar definidor de onde a narrativa deveria ser compreendida, encontra-se, então, uma solução deus ex machina: “John Demjaniuk era o número um da lista dos dez nazistas mais procurados 
pelo Centro Simon Wiesenthal, uma organização não-governamental que tem sede nos Estados Unidos e em Jerusalém, e que desde a década de 80 se dedica a procurar criminosos de guerra alemães". Qual a relevância de ressaltar na passagem o Centro Simon Wiesenthal frente ao desenrolar dos fatos apresentados? Ainda mais quando é de conhecimento geral que o ucraniano foi extraditado e julgado em Israel em 1988, sendo absolvido por falta de provas; ou seja, a localização dele era conhecida havia 20 anos, pelo menos. A intenção de se apropriar de duas fontes, sem gerar nenhum envolvimento, deixa poucas dúvidas discursivamente. Inverte-se o eixo da narrativa em busca de uma sobrevaloração dos fatos, algo que não está presente, mas que é acrescentado como se fosse fundamental. A ideia inicial de forjar um sentido de co-presença com o acontecimento em busca de credibilidade ganha uma nova perspectiva. Deslocar o espaço em que o repórter se posiciona para falar gera uma dimensão política que fica aquém da observação direta. Cria-se uma sensação de premência e prioridade que apaga o sentido primeiro de "asseverar o que se viu" para dar visibilidade à ideia de "narrar da única forma correta" - para o $\mathrm{JN}$ e a Globo, é claro.

A perda do referencial geográfico, e até mesmo temporal, também é possível através da passagem comensalista. O Jornal Nacional de 29 de maio de 2009 apresentou esta abertura da matéria: "Uma organização não-governamental internacional apresentou nesta sexta ao mundo previsões devastadoras sobre os efeitos das mudanças climáticas que atormentam o planeta. A poluição, principalmente a dos países ricos, foi identificada como a principal responsável por essa situação. É o que mostra, de Paris, a correspondente Sônia Bridi”. A África, fortemente atingida pelo problema, naquele dia fez um protesto pedindo reparação. A passagem, então, faz o fechamento da reportagem: "Ao dar uma face humana ao aquecimento global, o fórum espera sensibilizar os países ricos para um acordo, daqui a seis meses, na Conferência Mundial sobre o Clima, na Dinamarca. O novo tratado vai determinar em quanto cada país deve reduzir emissões de gases para impedir que o aquecimento passe dos $2^{\circ} \mathrm{C}$. Acima disso, as consequências seriam ainda mais catastróficas". Bridi fala com a romântica Torre Eiffel ao fundo sobre um céu azul-roseado; África e Genebra são os lugares da ação: em uma, os fatos se desenrolam; na outra, acontecerão. E Paris? Paris tem a acepção de "mundo", onde todos os sentidos se entrecruzam e imbricam. É o pano de fundo para guiar uma narrativa que se recusa a ir onde os fatos acontecem e não tem como atravessar o tempo para chegar ao futuro, quando os mandatários se reunirão. Fica, então, em lugar nenhum, em qualquer lugar, em "todos os lugares". É apenas um pano de fundo, um cenário glamouroso frente à pobreza e mortandade africana, já que agressores e agredidos, ilusoriamente, dividem o mesmo espaço - o mundo.

\section{Tão longe, tão perto}

É nesse jogo de intencionalidades não ditas que a verdade maior do jornalismo perde seu amparo. Não se admitem mentiras ou meias-verdades. O sentido de veracidade apresentado ao público - na eterna busca por ser objetivamente verdadeiro se constrói no movimento circular da credibilidade: é credível o jornalismo que trabalha com a verdade, e a verdade só tem 
valor se for amparada pela credibilidade jornalística. Ao buscar naturalizar sentidos metonímicos para reforçar a co-presença com o acontecimento, falseia-se com a verdade em troca do reforço no sentido de presença. Mas essa é uma presença "vazia", não tem uma função amparada pelo campo da mesma maneira que a passagem "de construção de presença", "[...] cuja função é tão somente realçar a proximidade do repórter em relação àquilo que noticia, enfatizando uma condição que subjaz todas as suas outras participações no telejornal, a de 'testemunha' do fato/fenômeno reportado (afinal, é ele que 'está no local')" (FECHINE; LIMA, 2008, p. 12-13).

O jornalismo se constrói tanto no "testemunho" quanto na "transmissão" da experiência. $\mathrm{O}$ mesmo acontece com as "experiências vividas" e "mediadas". Como estratégia de enunciação, o testemunho tem um valor simbólico superior à transmissão, assim como as experiências vividas são mais ricas e intensas do que as mediadas. Mas é justamente na combinação desses quatro itens que o campo jornalístico ancora a credibilidade, amplificando as relações em que esse valor é mais intenso e silenciando quando a intensidade é baixa - algo também presente nas relações cotidianas do público.

No telejornalismo, no entanto, a passagem tem um sentido de "construção de presença" intrínseco ao sentido que denota. Ao apagar esse sentido em determinadas passagens dos correspondentes estrangeiros, o Jornal Nacional - e de forma mais ampla o telejornalismo da Globo - exerce uma relação de comensalismo em que se apropria do acontecimento sem interagir com ele; cria um sentido de co-presença sem estar presente. Para justificar a ausên- cia in loco do repórter, editorializa os fatos através de enfoques culturais, políticos ou econômicos como se isso fosse a forma legítima de narrar a notícia. Apesar dos exemplos analisados serem todos de 2009, a prática é anterior e posterior a essa data. O tempo não é uma variável relevante para a análise, já que o uso da passagem comensalista está sedimentado desde a década de 1990. Mesmo antes disso, a Globo já usava os correspondentes estrangeiros como uma forma de reafirmar seu poderio econômico e tecnológico, tanto frente a outras emissoras quanto junto ao público. Com o crescimento do investimento de outras redes na área do jornalismo, principalmente Record e Band, a Globo perdeu a exclusividade na presença de repórteres no exterior. No entanto, criou uma prática que antes era exclusiva, particular, para definir um padrão jornalístico. Institucionalizado pelo tempo, o uso e a aparente aceitação do público, o comensalismo foi incorporado como prática legítima da narrativa do repórter, presente em todos os jornais da Globo e das emissoras que mantém correspondentes em seus quadros.

$\mathrm{O}$ mito idealmente perseguido de que o jornalismo "deve narrar de onde os fatos estão" para garantir a verdade e a credibilidade abre espaço para um mito que amálgama latitudes, longitudes, culturas e diferenças. Não importa que o testemunho da verdade presente na construção da presença seja falseado, desde que consiga gerar o sentido de credibilidade. Neste caso, o comensalismo não funciona na relação interespecífica entre o jornalismo e os leitores: apesar de viverem regularmente associados buscando "alimento" um no outro, uma das partes não tem receio de causar danos. 
BENETTI, Marcia. O jornalismo como gênero discursivo. Galáxia. n. 15. São Paulo: PUC-SP, 2008.

CHAPARRO, Manuel Carlos. Pragmática do Jornalismo: buscas práticas para uma teoria da ação jornalística. São Paulo: Summus, 1994.

CHARAUDEAU, Patrick. Discurso das mídias. São Paulo: Contexto, 2006.

FECHINE, Yvana; LIMA, Luisa Abreu e. Por uma sintaxe do telejornal: um estudo sobre a função da passagem na reportagem. VI Encontro da Sociedade Brasileira de Pesquisadores em Jornalismo (SBPJOR). Anais. São Bernardo do Campo: UMESP, 2008.

FORNARI NETO, Ernani. Dicionário prático de ecologia. São Paulo: Aquariana, 2001.

GOMES, Itânia Maria Mota; GOMES, Luana S. o contexto comunicativo nos telejornais da Rede Globo: uma análise do Bom Dia Brasil, Jornal Hoje, Jornal Nacional e Jornal da Globo. In: Comunicação audiovisual: gêneros e formatos. Maria Lília Dias de Castro (org). Porto Alegre: Sulina, 2007.

HAGEN, Sean. Jornalismo, mito e linguagem: uma abordagem teórica dos apresentadores-estrela. In: VIZEU, Alfredo (org). A Sociedade do Telejornalismo. Petrópolis: Vozes, 2008.

HALL, Stuart et al. A produção social das notícias: o mugging nos media.

In: TRAQUINA, Nelson (org.). Jornalismo: questões, teorias e "estórias". Lisboa: Vega, 1993.

KATZ, Elihu. Os acontecimentos mediáticos: o sentido de ocasião. In: TRAQUINA, Nelson (org.). Jornalismo: questões, teorias e "estórias". Lisboa: Vega, 1993.

MICHAELIS: moderno dicionário da língua portuguesa. Editora Melhoramentos. Disponível em: http://michaelis.uol.com.br/moderno/portugues/index.php?lingua=portugues-portugues\&palavra=comensalismo. Acesso em jun 2009.

MOLOTCH, Harvey; LESTER, Marilyn. As notícias como procedimento intencional: acerca do uso estratégico de acontecimentos de rotina, acidentes e escandâlos. In: TRAQUINA, Nelson (org.). Jornalismo: questões, teorias e "estórias". Lisboa: Vega, 1993.

MOUILLAUD, Maurice e PORTO, Sérgio D. (orgs.). O Jornal: da forma ao sentido. 
MOREIRA, Fabiane Barbosa. Os valores-notícia no jornalismo impresso: análise das "características substantivas" das notícias nos jornais Folha de São Paulo, $O$ Estado de São Paulo e O Globo. Dissertação de Mestrado. Programa de Pós-Graduação em Comunicação e Informação. Porto Alegre: Universidade Federal do Rio Grande do Sul, 2006.

RODRIGUES, Adriano Duarte. Estratégia da Comunicação. 2. ed. Lisboa: Editorial Presença, 1997a.

RODRIGUES, Adriano Duarte. Comunicação e Experiência. BOCC, 1997b. Disponível em: http://www.bocc.ubi.pt/pag/rodrigues-adriano-comunicacao-experiencia.html. Acesso em jun 2009.

VAN DIJK, Teun. La noticia como discurso: comprensión, estructura y produción de la información. Barcelona: Paidós, 1990.

Estudos em Jornalismo e Mídia está sob a licença Creative Commons 2.5 